\title{
Common coeliacomesenteric trunk: a computed tomography radiological study
}

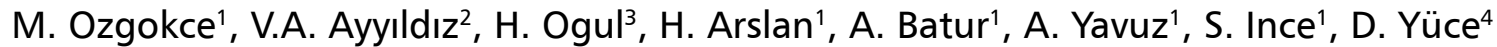 \\ ${ }^{1}$ Department of Radiology, Yuzuncu Yıl University, Van, Turkey \\ ${ }^{2}$ Radiology Clinic, Siirt State Hospital, Turkey \\ ${ }^{3}$ Department of Radiology, Erzurum Ataturk University, Turkey \\ ${ }^{4}$ Departmant of Preventive Oncology, Hacettepe University, Ankara, Turkey
}

[Received: 20 September 2017; Accepted: 29 January 2018]

\begin{abstract}
Background: There is an increasing trend for administration of invasive radiological interventions, laparoscopic surgery, and transplantation procedures in recent years, and determining the vascular variations prior to these procedures is crucially important. Coeliacomesenteric trunk (CMT) is among these variations. This study aimed to retrospectively evaluate this rare anomaly by computed tomography (CT). Materials and methods: A total of 1000 CT angiography images were analysed retrospectively, and the patients with mesenteric and coeliac arteries arising from the abdominal aorta with a single root were identified. The level that CMT arose, and its branching patterns were determined individually for all patients.

Results: Ten patients ( 6 males and 4 females) with a mean age of 50.2 years (17-87 years) had CMT in CT images.

Conclusions: The knowledge of variations in the CMT prior to vascular or laparoscopic interventions will contribute to early intervention in case of a complication, or to avoid from a potential damage. (Folia Morphol 2018; 77, 4: 683-686)
\end{abstract}

Key words: computed tomography angiography, coeliacomesenteric trunk, vascular variation

\section{INTRODUCTION}

Determining the anatomical variations of vasculature prior to interventional radiological and surgical procedures is gaining importance, due to recent increases in these applications. There are plenty of reports about the vascular variations that identified during cadaver or imaging studies.

Abdominal viscera get blood supply mostly from the coeliac artery (CA) and the superior mesenteric artery (SMA). The CA is the major ventral vessel that branches from the abdominal aorta (AA) first [18], at T11-12 intervertebral disc level [1]. Abnormal embryological development of the ventral splanchnic arteries may lead to different vascular variations [2].

The common coeliacomesenteric trunk (CMT) is the rarest abdominal vascular abnormality with a prevalence of $1-2.7 \%[2,15,20]$. It anatomically comprises a common branching-trunk of CA and SMA. Variations in prevalence and branching pattern of this anatomical structure were reported both at individual and population levels. Identification of these variations prior to surgical and invasive vascular interventions (including but not limited to abdominal laparoscopic vascular surgeries, liver or kidney transplants, oncological resections, and vascular chemoembolisation) has particular importance to avoid from fatal outcomes due to an injury of these structures [16].

Under the light of current evidence, we aimed to evaluate the origin and branching patterns of the rarely occurring CMT using computed tomography (CT) angiography. 


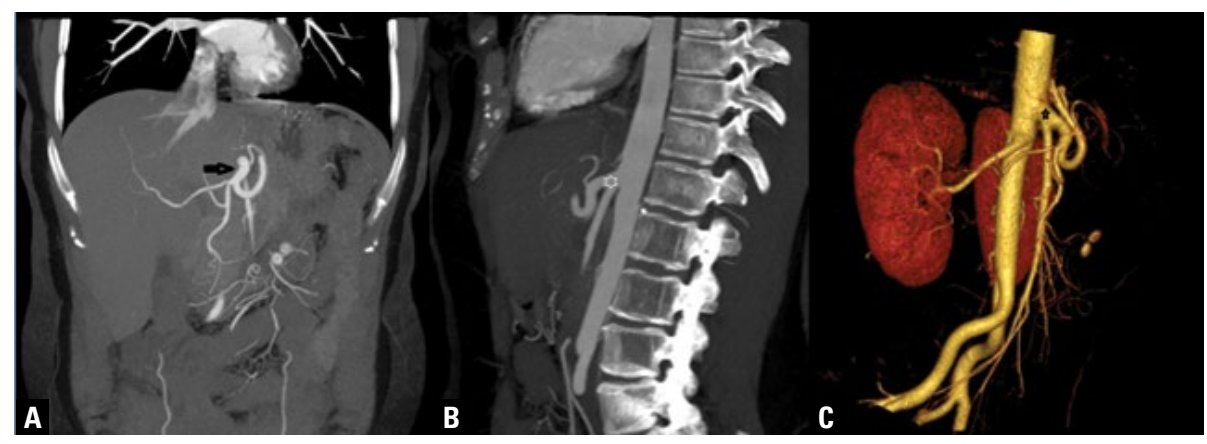

Figure 1. Coronal (A), sagittal (B), and volume rendered (C) images of the common coeliacomesenteric trunk (arrow and asterisks).

\section{MATERIALS AND METHODS}

This study was conducted at the Van Yuzuncu Yil University Faculty of Medicine, Radiology Department, and a total of 1000 abdominal CT angiographies (Siemens Medical Systems, Erlangen, Germany, 16 slice, $120 \mathrm{kV}, 125$ effective $\mathrm{mA}, 16 \times 1.5 \mathrm{~mm}$ collimation, $3 \mathrm{~mm}$ slice thickness and $512 \times 512$ matrix) taken for any indication between August 2015 and January 2017 were evaluated retrospectively with regard to CMTs. The CT assessments with intense vascular calcification, poor contrast resolution, marked tortuosity, and non-contrasted scan were excluded from the evaluations. Local ethical committee of the university approved the study protocol (approval number: B.30.2.YYU.0.01.00.00/151).

An extensive assessment of the CT scans revealed 10 patients with CMT (7 females, 3 males). Age, CMT output level, calibration of the vascular structures forming the CMT, and aorto-truncal angle were recorded for those patients. All measurements were obtained from multiplane reformatted images (Fig. 1).

\section{RESULTS}

Mean age of the 10 patients with CMT was 50.2 years (17-87 years). Seven cases had abdominal symptoms of pain, swelling, dyspepsia and cramps after meals, 1 patient had thoracic pain and weakness, 1 patient was a cancer survivor on routine follow-ups, and 1 patient was in puerperium after a caesarean delivery with a previous history of pancreatitis, and had elevated tumour-marker levels. The mean (minmax) diameters were $8.42 \mathrm{~mm}(5.2-11.6 \mathrm{~mm})$ for the CMT, $6.22 \mathrm{~mm}(5.4-7.3 \mathrm{~mm})$ for the CA, $4.72 \mathrm{~mm}$ $(2.7-7.2 \mathrm{~mm})$ for the splenic artery, $2.59 \mathrm{~mm}$ $(1.7-5 \mathrm{~mm})$ for the left gastric artery, $4.53 \mathrm{~mm}$ $(2.3-8.3 \mathrm{~mm})$ for the common hepatic artery, $3.43 \mathrm{~mm}$ $(2-4.9 \mathrm{~mm})$ for the main hepatic artery, and $5.58 \mathrm{~mm}$ (3.6-9.2 $\mathrm{mm}$ ) for the SMA.
The CMT branched out from the aorta at L1-L2 intervertebral disc level in 2 patients, T12-L1 intervertebral disc level in 2 patients, L1 vertebral body level in 3 patients, L1 inferior end plate level in 2 patients, and $\mathrm{T} 12$ inferior end plate level in 1 patient. The mean aortotruncal angle between the CMT and abdominal aorta that measured in the sagittal plane images was $26.65^{\circ}$, and ranged between $13.5^{\circ}$ and $38^{\circ}$.

\section{DISCUSSION}

Identification of vascular variations is important both for anatomical and embryological knowledge, and also crucial for avoiding unintended damages during invasive surgical and radiological procedures.

Dorsal, lateral, and ventral arteries originate from the abdominal aorta and collaterally anastomose with each other during embryonal development. These groups of arteries supply blood to parietal organs, urogenital system, and digestive system, respectively. The reshaping of double vitelline (primitive intestinal) arteries to supply intestinal tube accompanies cephalocaudal and lateral embryonal convolution [17]. The CA, SMA and inferior mesenteric artery (IMA) originates from the $10^{\text {th }}, 13^{\text {th }}, 21^{\text {st }}$, or $22^{\text {nd }}$ metameric vitelline arteries that supply the yolk sac of the embryo, and supply blood to foregut, midgut, and hindgut, respectively $[14,17]$. Remaining metameric arteries, and in between anastomoses, namely Tandler's longitudinal anastomoses, disappear during embryonal development [4]. The erroneous persistence of an anastomosis or a primitive artery may result with a variant CA, SMA, or IMA in adults [11]. Likewise, we have identified that the CMT originated from the CA in our cases.

The vascular variations are mostly detected incidentally in imaging studies prior to invasive procedures, or during cadaver dissections. Nevertheless, advances in imaging techniques made non-invasive detection of the vascular variations in three-dimen- 
sional reconstructed images easier [6]. Recently, several European researchers and their colleagues found that the CMT incidence was 1.3\% [2], Yi et al. [20] reported that a common CA and SMA branch, the CMT, was found in $1.5 \%$ of magnetic resonance imaging and CT imaging studies, and Matusz et al. [10] reported the CMT prevalence of $0.68 \%$ in their large series of 10,750 cases. Our results on the prevalence of CMT were similar with the previous studies and revealed a similar proportion of $1 \%$ in our series.

There are different reports about the origins of CMT, CA, SMA, and IMA in the literature. Anatomically the origins of the CA, SMA, and IMA from the AA corresponds to the levels right below the aortic hiatus, L1-L2 intervertebral disc level, and 3-4 cm above the aortic bifurcation, respectively [16]. The studies of Nonent et al. [14], and Cicekcibasi et al. [3] found variations of these origins, and reported that CMT, CA, SMA, and IMA originates from a common origin, which was not observed in our cases. Wadhwa and Soni [19] reported that CMT was separated directly from the AA at the $\mathrm{T} 12$ and $\mathrm{L} 1$ intervertebral disc levels in $73.3 \%$ of the cases, and at the L1 and higher levels in $26.6 \%$ of the cases. Another study by Hofman and Watson [5] reported that CMT separated at the T12 level and originated from the vertebral level between $\mathrm{T} 11$ and $\mathrm{L} 2$. Our results revealed that separation level was L1-L2 intervertebral disc in 2 patients, T12-L1 intervertebral disc in 2 patients, L1 vertebral body in 3 patients, L1 inferior end plate in 2 patients, and T12 inferior end plate in 1 patient, which all originated from the T11-L2 vertebral space in consistence with the literature data. A pre-estimation of the vertebral level is particularly important for the acute haemorrhage incidents during abdominal angiographies.

To the best of our knowledge, there is no data about the diameter range of the CMT in the literature, but there are several reports about the CA. These previous studies vary regarding the diameter of the $\mathrm{CA}$ at origin, which has been reported as $7-14 \mathrm{~mm}$ by Moncada et al. [13], 8-21 mm by Michels [12], and 8-40 $\mathrm{mm}$ by Cavdar et al. [2]. Our results showed that CA diameters ranged between 5.4 and $7.3 \mathrm{~mm}$ and were thinner than normal. This was thought to result with decreased blood-flow to vascular bed, and considered as a possible explanation of the nonspecific abdominal pain in our cases.

Since the CMT provides blood-flow to major abdominal organs, a damage or thrombosis may result with significant consequences including abdominal aneurysms [9, 15], aneurysm-related compression [1], chronic occlusive disease and coeliac trunk compression syndrome [7], and thrombosis-related gastrointestinal necrosis [8]. Atherosclerosis of CMT may also cause non-specific abdominal pain, and this vascular variation should be kept in mind for the differential diagnosis of cases with intermittent abdominal pain. Moreover, if cases with CMT should undergo invasive vascular procedure or surgery, radiographic images should be analysed carefully prior to the procedure.

\section{CONCLUSIONS}

This study included 1000 cases, which is one of the largest series in the literature. Our results showed that prevalence of CMT was about $1 \%$, which is a rare but significant proportion when the increasing number of invasive vascular or surgical procedures are encountered. Also, presence of the CMT may be an explanation for the long-term unexplained abdominal pain. By these features, CMT possesses an important entity, and clinicians should aware of this vascular variation during patient management.

\section{REFERENCES}

1. Ailawadi G, Cowles RA, Stanley JC, et al. Common celiacomesenteric trunk: aneurysmal and occlusive disease. J Vasc Surg. 2004; 40(5): 1040-1043, doi: 10.1016/j. jvs.2004.08.028, indexed in Pubmed: 15557926.

2. Cavdar S, Sehirli U, Pekin B. Celiacomesenteric trunk. Clin Anat. 1997; 10(4): 231-234, doi: 10.1002/(SICI)10982353(1997)10:4<231::AID-CA2 > 3.0.CO;2-V, indexed in Pubmed: 9213038.

3. Ciçekcibaşi $A E$, Uysal II, Seker $M$, et al. A rare variation of the coeliac trunk. Ann Anat. 2005; 187(4): 387-391, doi: 10.1016/j.aanat.2005.02.011, indexed in Pubmed: 16163851.

4. Douard R, Chevallier JM, Delmas V, et al. Clinical interest of digestive arterial trunk anastomoses. Surg Radiol Anat. 2006; 28(3): 219-227, doi: 10.1007/s00276-006-0098-8, indexed in Pubmed: 16547602.

5. Hofman S, Watson R. Porta hepatis irradiation. Int J Radiat Oncol Biol Phys. 1978; 4: 333-336.

6. lezzi R, Cotroneo AR, Giancristofaro D, et al. Multidetector-row $C T$ angiographic imaging of the celiac trunk: anatomy and normal variants. Surg Radiol Anat. 2008; 30(4): 303-310, doi: 10.1007/s00276-008-0324-7, indexed in Pubmed: 18286222.

7. Loukas M, Pinyard J, Vaid S, et al. Clinical anatomy of celiac artery compression syndrome: a review. Clin Anat. 2007; 20(6): 612-617, doi: 10.1002/ca.20473, indexed in Pubmed: 17309066.

8. Lovisetto F, Finocchiaro De Lorenzi G, Stancampiano P, et al. Thrombosis of celiacomesenteric trunk: report of a case. World J Gastroenterol. 2012; 18(29): 3917-3920, doi: 10.3748/wjg. v18.i29.3917, indexed in Pubmed: 22876046. 
9. Mammano E, Cosci M, Zanon A, et al. Celiomesenteric trunk aneurysm. Ann Vasc Surg. 2009; 23(2): 257. e7-257.10, doi: 10.1016/j.avsg.2008.08.015, indexed in Pubmed: 18809283.

10. Matusz P, Miclaus GD, Ples $H$, et al. Absence of the celiac trunk: case report using MDCT angiography. Surg Radiol Anat. 2012; 34(10): 959-963, doi: 10.1007/s00276-0120989-9, indexed in Pubmed: 22689084.

11. McNulty JG, Hickey N, Khosa F, et al. Surgical and radiological significance of variants of Bühler's anastomotic artery: a report of three cases. Surg Radiol Anat. 2001; 23(4): 277-280, indexed in Pubmed: 11694975.

12. Michels NA. Blood suly and anatomy of the uer abdominal organs. JB Lippincott Co., Philadelphia 1956: 139-141.

13. Moncada R, Reynes $C$, Churchill $R$, et al. Normal vascular anatomy of the abdomen on computed tomography. Radiol Clin North Am. 1979; 17(1): 25-37, indexed in Pubmed: 461742.

14. Nonent $M$, Larroche $P$, Forlodou $P$, et al. Celiac-bimesenteric trunk: anatomic and radiologic description--case report. Radiology. 2001; 220(2): 489-491, doi: 10.1148/radiology.220.2.r01au34489, indexed in Pubmed: 11477258.

15. Obara H, Matsumoto K, Fujimura N, et al. Reconstructive surgery for a fusiform common celiomesenteric trunk aneurysm and coexistent abdominal aortic aneurysm: report of a case. Surg Today. 2009; 39(1): 55-58, doi: 10.1007/s00595-008-3784-9, indexed in Pubmed: 19132470.

16. Prakash, Mokhasi V, Rajini T, et al. The abdominal aorta and its branches: anatomical variations and clinical implications. Folia Morphol. 2011; 70(4): 282-286, indexed in Pubmed: 22117246.

17. Sadler TW, Langman J. Langman's medical embryology. 12 th ed. Wolters Kluwer Health/Lippincott Williams \& Wilkins, Philadelphia 2012: 384

18. Selvaraj L, Sundaramurthi I. Study of normal branching pattern of the coeliac trunk and its variations using CT angiography. J Clin Diagn Res. 2015; 9(9): AC01-AC04, doi: 10.7860/JCDR/2015/12593.6523, indexed in Pubmed: 26500893.

19. Wadhwa A, Soni SA. Composite study of coeliac trunk in 30 adult human cadavers - its clinical implications. Global J Med Res. 2011; 11(1).

20. Yi SQ, Terayama $H$, Naito $M$, et al. A common celiacomesenteric trunk, and a brief review of the literature. Ann Anat. 2007; 189(5): 482-488, doi: 10.1016/j.aanat.2006.11.013, indexed in Pubmed: 17910402. 